\title{
Applying Systems Engineering to the Lunabotics Mining Competition Cap- stone Design Challenge
}

\section{Ms. Lisa Guerra, NASA Headquarters}

Lisa Guerra has 27 years of experience in the NASA aerospace community. Ms. Guerra is currently affiliated with NASA Headquarters working policy issues. She recently completed a 2-year assignment with the UTeachEngineering Program developing a model high school engineering course. She also fulfilled an assignment from NASA to establish a systems engineering curriculum at The University of Texas at Austin, as a pilot for national dissemination. Ms. Guerra's previous position at NASA Headquarters was Director of the Directorate Integration Office in the Exploration Systems Mission Directorate. In that position, her responsibilities involved strategic planning, international cooperation, cross-directorate coordination, architecture analysis, and exploration control boards. Ms Guerra also spent 3 years at the Goddard Space Flight Center as Program Integration Manager for future high-energy astrophysics missions, particularly the James Webb Space Telescope. She began her career at the Johnson Space Center working for Eagle Engineering and SAIC, focused on conceptual design of advanced spacecraft for human missions to the Moon and Mars.

Ms. Guerra earned a B.S in Aerospace Engineering and a B.A. in English from the University of Notre Dame. She received a Master of Science degree in Aerospace Engineering from the University of Texas at Austin.

\section{Ms. Gloria A. Murphy, NASA}

Gloria A. Murphy is currently the Project Manager of the Lunabotics Mining Competition at NASA's John F. Kennedy Space Center (KSC), Florida. Ms. Murphy began her career in 1990 with NASA as a cooperative student in the Payload Processing Directorate. Her first engineering position was an experiment test engineer for the Spacelab Program. In 1998, Ms. Murphy began working on the International Space Station (ISS) Program as a systems engineer for the Multi Element Integrated Test (MEIT). She continued to develop her engineering skills working with many engineering disciplines for testing various hardware and software interfaces between the U.S. and international elements on the Space Station. Her duties included extensive travel to Lyndon B. Johnson Space Center, Marshall Space Flight Center, Canada and Japan. Ms. Murphy joined the Launch Services Program in 2003 as an integration engineer for Pegasus and Taurus missions. In this position, she concentrated on the interfaces between the launch vehicle and the spacecraft. Ms. Murphy joined the Education Office in 2007 where she continues to serve as the project manager for the Lunabotics Mining Competition. Ms. Murphy earned a Bachelor of Arts degree in Psychology from the University of Central Florida, a Bachelor of Science degree in Electrical Engineering from the University of Central Florida and a Master of Science degree in Computer Science from the Florida Institute of Technology.

\section{Ms. Lisa D. May, NASA Headquarters}

Ms. May is currently the Lead Program Executive for NASA's Mars Exploration Program. In addition, she is the Program Executive for the MAVEN mission launching to Mars this year, Mars Technology, and Mars Sample Return. She leads budget and review processes and supports the Division Director in technical decision making. Prior to joining the Mars program, Ms. May held a number of positions enabling NASA science missions, including Special Assistant for Strategic Planning at Headquarters and Senior Proposal Manager at NASA Goddard.

Before Ms. May signed on with NASA, she ran a systems engineering and proposal management company, Jackson-May Associates. Her clients included small companies, major aerospace firms, and NASA.

Ms. May has a master's degree in Mechanical Engineering and a bachelor's in Speech Communications, both from the University of Virginia. In addition to her technical career, she has experience in journalism and currently is the female narrator for NASA's ScienceCasts. 


\section{Applying Systems Engineering to the Lunabotics Mining Competition Capstone Design Challenge}

\section{Introduction}

Lunabotics Mining Competition is a university-level challenge intended for the capstone design experience. The basic challenge is for student teams to design and build a remote-controlled or autonomous excavator, called a lunabot that can maneuver over rough, simulated lunar terrain and collect and deposit a minimum of 10 kilograms of lunar simulant within 10 minutes. In order to produce and demonstrate a viable design, students are required to apply systems engineering techniques. This paper addresses the application of systems engineering as an integral part of the Lunabotics design challenge. The systems engineering portion of the Lunabotics competition requires a paper to be submitted prior to the actual mining event. The systems engineering scoring rubric requires that students demonstrate a variety of processes and practices - from requirements development to design reviews to trade studies, with professional engineers judging the submissions. University teams vie for the best systems engineering paper award, and their paper scores contribute to the grand prize score.

This paper highlights the qualities of the winning systems engineering papers from the three years of the Lunabotics design challenge. Emphasis is placed on the understanding of systems engineering demonstrated by the university teams, as well as compliance with the stated challenge requirements. The paper also compares the results of the systems engineering paper scores with the performance of the lunabots in the challenge. Finally, the paper discusses the perspective of the paper judges, all practicing systems engineers, on common student misunderstandings about systems engineering and the plans to refine the scoring rubric for future competitions. By demonstrating the application of systems engineering to the Lunabotics design challenge, this paper makes the case for inclusion of systems engineering into university-level capstone curricula to improve engineering design.

\section{Background on the Lunabotics mining competition}

NASA's annual Lunabotics Mining Competition is an international, university-level competition designed to engage and retain students in science, technology, engineering and mathematics (STEM). NASA benefits from the competition by encouraging the development of lunar excavation concepts that may result in clever ideas and solutions with practical application to actual lunar excavation devices or payloads. The challenge is for students to design and build a lunabot that can mine and deposit a minimum of 10 kilograms of lunar simulant within 10 minutes. The lunar simulant used in the competition is Black Point 1 (BP-1) ${ }^{1}$, which has very similar physical properties to those of lunar soil. The complexities of the challenge include the abrasive characteristics of BP-1, weight and size limitations on the lunabot, and the requirement to only operate the lunabot - either telerobotically — from a remote mission control center or autonomously. In addition, the lunabots cannot employ any fundamental physical processes (e.g., suction or water cooling), gases, fluids, or consumables that would not work in the lunar environment. To mine successfully, the teams must consider a number of design and operational factors such as dust tolerance and projection, communications, vehicle mass, energy/power required, and optional full autonomy. 
The competition has a number of prize categories that result in individual prizes and also contribute toward the score for the overall prize. Numerical scores are tallied for all monetary prize awards. The judges' evaluation criteria, from which the scores are based, are provided to the competitors as part of the initial competition rules. For the paper categories, including the systems engineering paper, the judges individually review and score the papers, then meet to discuss and decide the winners. For the on-site mining award, scores are calculated from a variety of performance and design factors, with the highest total score determining the winner. For all categories, the teams earn points towards the Joe Kosmo Award for Excellence.

Undergraduate and graduate student teams enrolled in a U.S. or international college or university are eligible to enter. Design teams must include: at least one faculty member with a college or university and at least two undergraduate or graduate students. NASA has not set an upper limit on team members, but the team should have a sufficient number of members to successfully set up and remotely operate their lunabot. Registration is limited to one team per university campus. Internationally, registration is limited to 10 teams per country. In 2012, 791 students participated on 55 teams from 28 states and 8 countries including Bangladesh, Canada, Colombia, India, Mexico, Romania, South Korea and the United States.

\section{Motivation for teaching systems engineering}

NASA, the sponsoring agency of the Lunabotics Mining Competition is undergoing a generational transition. After decades of space shuttle missions close to Earth, NASA is charged to send astronauts to the lunar vicinity, to asteroids, and eventually to Mars and beyond. In order to fulfill the scope of these grand exploration plans, NASA will need to design, build and operate numerous systems - from planetary transfer vehicles to robotic rovers to space suits. All of the key systems will have to work together for years, in remote environments. It will not be enough to have systems that operate separately, but rather systems that meet overarching sets of requirements and function together. The demand for engineers familiar with systems engineering, as well as actual systems engineers, will be higher than ever.

Recognizing this future need for systems engineers in the aerospace community, NASA has sponsored two higher-education curriculum efforts to introduce systems engineering into undergraduate engineering programs. The first effort involved the development, pilot, and dissemination of an undergraduate, systems engineering course ${ }^{2}$ designed for integration with the senior capstone design experience required in all undergraduate engineering degree programs. At the undergraduate level, the goal is to teach the fundamentals of systems engineering such that future practicing engineers are familiar with the concepts and processes to be exercised further in the work environment. Given NASA's involvement in the course development, the perspective is from the aerospace community with an emphasis on what it takes to put a space system together. The systems engineering course approach tends toward the practical rather than the theoretical with an emphasis on concrete examples. The course exposes students to various techniques in getting the systems engineering job done, such as concept of operations, requirements development, trade studies and decision analysis, failure modes effects analysis, and cost/schedule modeling. The order of the some 24 different topics follows, to some extent, the system life cycle of development, with system formulation topics at the beginning and system implementation topics later. 
The second effort originated from NASA's sponsorship of engineering faculty ideas for challenging capstone design projects. One of the winning proposals came from Auburn University's Drs. David Beale and Daniel Harris - to develop a senior design course on the topic "Lunar Regolith Excavation for Oxygen Production and Outpost Emplacement." The course provides basic educational materials intended to expose students to engineering analysis and design skills necessary for non-Earth-based machines, particularly systems for operational use on the lunar surface. Specific educational topics include an overview of the lunar environment, mechanical and electromechanical components for the lunar environment, Computer-Aided Engineering tools, and lunar heat transfer. In addition, the course teaches students to use the NASA systems engineering processes as a way to provide engineering discipline in complex design projects. The Auburn senior design course with integrated systems engineering is the basis of the Lunabotics Mining Competition design challenge. Note that both of these NASAfunded curriculum efforts are readily accessible to universities worldwide, regardless of participation in Lunabotics. The intent is to instill viable practices of space systems design and systems engineering in undergraduate engineering education.

\section{The systems engineering paper competition}

The systems engineering portion of the Lunabotics competition results in a paper submitted prior to the actual mining event. University teams vie for the best systems engineering paper award, as their paper scores contribute to the grand prize score. The Lunabotics systems engineering paper scoring rubric involves three categories: content, intrinsic merit, and technical merit. Table 1 summarizes the elements of the scoring rubric, as provided to the students at the beginning of the challenge year.

A minimum score of 15 out of 20 possible points must be achieved to qualify to win in the systems engineering paper category. Two NASA judges, all of whom are practicing systems engineers, score each paper. The total scores are averaged to achieve the official paper score. Large disparities amongst scores are discussed with the entire judges panel, with a third judge often assigned to review the paper in question, in order to resolve the score. Despite the assumption that one paper may rise to the top of the fifty or so entries, every year of the competition has resulted in a second round of judging. Round two involves a smaller set of judges willing to read the best papers, usually with tied scores, discussing the exceptional merits of each, and deciding the winner. The winning papers thus far include:

- 2012: Montana State University, The Montana ALE (Autonomous Lunar Excavator)

- 2011: John Brown University, Team Golden Eagles

- 2010: Auburn University, Team Pumpernickel

Examples from each of these papers are presented here to demonstrate best practices with respect to the scoring rubric. 
Table 1 - The Lunabotics Systems Engineering Paper Scoring Rubric from the 2012 Design Challenge.

\begin{tabular}{|c|c|c|c|c|c|}
\hline \multicolumn{6}{|c|}{ Lunabotics Systems Engineering Paper Scoring Rubric } \\
\hline Elements & 4 & 3 & 2 & 1 & 0 \\
\hline $\begin{array}{l}\text { Content: } \\
\text { - } \quad \text { Formatted professionally, } \\
\text { clearly organized, correct } \\
\text { grammar and spelling, } \\
\text { maximum of } 20 \text { pages not } \\
\text { counting the cover and } \\
\text { source pages only; } 12 \text { font } \\
\text { size; single spaced. No } \\
\text { appendices allowed. } \\
\text { - } \text { Cover page } \\
\text { - Introduction } \\
\text { - } \text { Purpose } \\
\text { - Sources } \\
\end{array}$ & $\begin{array}{c}\text { All five elements } \\
\text { are } \\
\text { exceptionally } \\
\text { demonstrated }\end{array}$ & $\begin{array}{l}\text { Five elements } \\
\text { are clearly } \\
\text { demonstrated }\end{array}$ & $\begin{array}{l}\text { Four elements } \\
\text { are clearly } \\
\text { demonstrated }\end{array}$ & $\begin{array}{l}\text { Three or less } \\
\text { elements are } \\
\text { clearly } \\
\text { demonstrated }\end{array}$ & $\begin{array}{c}\text { Zero } \\
\text { elements are } \\
\text { clearly } \\
\text { demonstrated }\end{array}$ \\
\hline 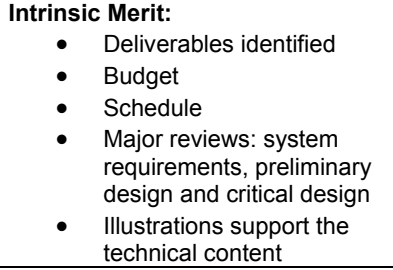 & $\begin{array}{c}\text { All five elements } \\
\text { are } \\
\text { exceptionally } \\
\text { demonstrated }\end{array}$ & $\begin{array}{l}\text { Five elements } \\
\text { are clearly } \\
\text { demonstrated }\end{array}$ & $\begin{array}{l}\text { Four elements } \\
\text { are clearly } \\
\text { demonstrated }\end{array}$ & $\begin{array}{l}\text { Three or less } \\
\text { elements are } \\
\text { clearly } \\
\text { demonstrated }\end{array}$ & $\begin{array}{c}\text { Zero } \\
\text { elements are } \\
\text { clearly } \\
\text { demonstrated }\end{array}$ \\
\hline $\begin{array}{l}\text { Technical Merit: } \\
\text { - } \text { Concept of operations } \\
\text { - } \text { System Hierarchy } \\
\text { - } \text { Interfaces defign } \\
\text { - Requirements definition } \\
\text { - } \text { Design margins } \\
\text { - Risk-off assessment } \\
\text { - Reliability } \\
\text { - } \text { Rerification } \\
\text { - } \text { validatioment and checkout } \\
\text { - Use of system life cycle }\end{array}$ & \multicolumn{5}{|c|}{ One point for each element exceptionally demonstrated up to twelve points. } \\
\hline
\end{tabular}

The content category focuses on professional format, valid sources, and addressing the objectives of both the systems engineering paper and the design competition. The paper has a page limit of 20 pages. This limit forces the students to succinctly address the key elements of the rubric with careful selection of supporting data and figures. Thus, the content category emphasizes the importance of submitting a professional document. Example elements addressing this category include:

1. Appropriate references, particularly related to systems engineering, such as the following from both the Auburn ${ }^{4}$ and John Brown ${ }^{5}$ papers: "Beale, D. and Bonometti, J. "Chapter 2: Systems Engineering (SE) - The Systems Design Process". http://www.eng.auburn.edu/ dbeale/ESMDCourse/Chapter2.htm", and

2. Clear purpose statements, such as the following from the Montana State ${ }^{6}$ paper: "This paper will summarize the goals of MSU's lunar excavator project, known as the Autonomous Lunar Explorer (ALE), along with the engineering process that the MSU team is using to fulfill these goals, according to NASA's systems engineering guidelines...Each student design produced for the competition is meant to serve as a possible inspiration or proof-ofconcept for future NASA projects. The efficient realization of a long-term human presence 
on the Moon will require astronauts to make use of local resources. Lunar soil, better known as regolith, can be processed to obtain vital substances (e.g. water and oxygen); therefore, machinery that mines and transports regolith is likely to be an important component of future moon missions. Thus, the challenges posed by the Lunabotics Mining Competition are directly relevant to NASA's goals. The competition is also intended to promote workforce development in science, technology, engineering, and mathematics (STEM) disciplines, by engaging college students in an exciting, challenging project that will provide them with realistic engineering experience."

Intrinsic merit requires students to address the management dimensions to systems engineering, including the budget, schedule, major design reviews, and the identification of key design deliverables. For the budget category, the winning papers identified their sources of funding, an accounting of the preliminary costs, as well as the actual expenses detailed to the subsystem and part levels. The Auburn ${ }^{4}$ paper also demonstrated how design decisions, such as whether to use skid steer, are based on both technical and budget concerns. Systems engineering paper submissions are required to include a schedule for the design and build efforts. Most papers include a Gantt chart, showing the beginning and end dates for the various activities, culminating with the competition in May, as shown in Figure 1. The schedules usually represent the preliminary planning for the design project. The winning papers address the need to revise schedules as work progresses and teams advance through the system life cycle of reviews, as noted in the Montana State ${ }^{6}$ paper: "The schedule...proved impossible to meet, and had to be revised by the team at the time of the Production Readiness Review. The updated target deadlines for the remaining portions of the project are as of the PRR date."

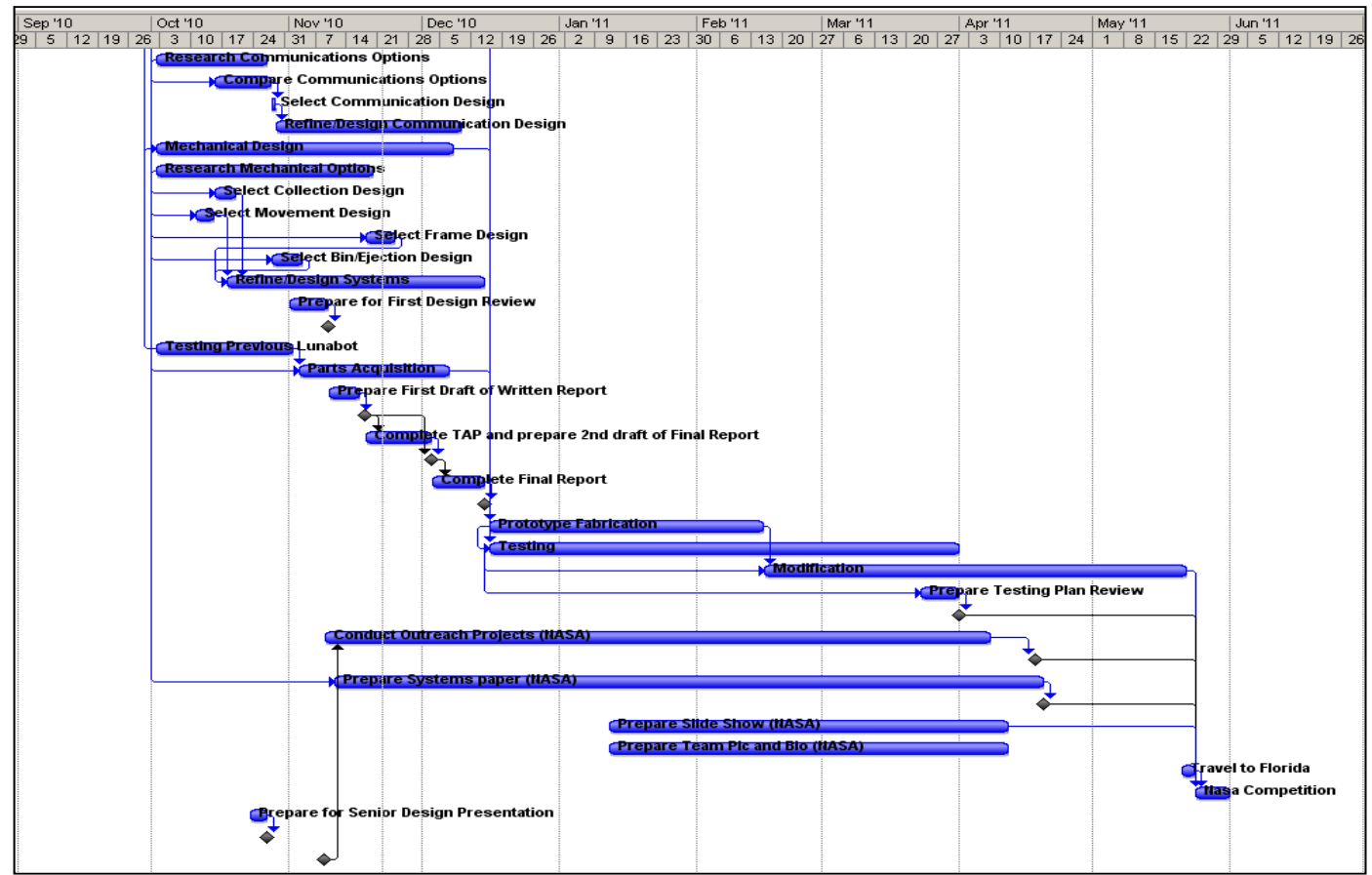

Figure 1 - Example Gantt chart from the John Brown University Lunabotics Project ${ }^{5}$. 
Most of the systems engineering paper submissions have neglected the topic of design reviews. By addressing the design reviews, teams show a level of professional discipline in progressing their design through stages of maturity and making key design decisions as a result of conducting the reviews. The John Brown University ${ }^{5}$ paper discussed the impact of their Critical Design Review (CDR): "One critical decision made in the electrical CDR was to use only one instead of two Arduino boards for the Control Subsystem. This reduced the complexity of the design as well as the mass of the lunabot. The mechanical CDR confirmed the design decisions and no major changes were made." The winning papers also articulated the major design reviews conducted and the need for the design review, as outlined in Table 2. Requiring student design teams to conduct design reviews also enables the involvement of the faculty, which can vary significantly. This benefit of conducting key milestone reviews is noted by the Montana State University ${ }^{6}$ paper: "Each review allowed the project advisers, other faculty members, and professionals in related fields to critique the team's plans and suggest improvements." The John Brown University ${ }^{5}$ team also included "staff and machinists from a local machine shop" as part of the audience to ensure the producibility of their design.

Table 2 - Major design reviews of the Montana State University ALE Project ${ }^{6}$.

\begin{tabular}{|l|l|l|}
\hline Review & Purpose & Pass Date \\
\hline System Requirements & $\begin{array}{l}\text { Ensure that the team has properly understood } \\
\text { and specified the requirements of the project. }\end{array}$ & September 16, 2011 \\
\hline Preliminary Design & $\begin{array}{l}\text { Establish that the basic, system-level design } \\
\text { proposed by the team is solid and practical. }\end{array}$ & October 7, 2011 \\
\hline Critical Design & $\begin{array}{l}\text { Ensure that the design is complete, and check all } \\
\text { of its details for flaws. }\end{array}$ & December 2, 2011 \\
\hline Production Readiness & $\begin{array}{l}\text { Review the team's plans for manufacturing and } \\
\text { testing the project, checking them for } \\
\text { completeness and practicality. }\end{array}$ & January 21, 2012 \\
\hline
\end{tabular}

The technical merit category carries the highest point value. Technical merit elements include concept of operations, systems hierarchy, system interfaces, requirements definition, trade studies, and risk assessment. Table 1 lists all the technical merit elements contributing to 12 of the overall 20 possible points. The purpose for including a concept of operations in the rubric is to help students understand the need to view their system design from the perspective of the end user. They are required to break down the operations the lunabot must perform, including: navigate to mining area, excavate simulant, navigate to bin, and deposit regolith. Some systems engineering papers included a list of lunabot actions, while stronger submissions derived the operational tasks from the functional system requirements. Others, such as the John Brown University ${ }^{5}$ paper, represented their concept of operations as a competition-timing budget as shown in Table 3. 
Table 3 -Example concept of operations from the John Brown University paper ${ }^{5}$.

\begin{tabular}{|c|r|l|}
\hline Time (minutes) & \% of Total Time & Description \\
\hline 1 & 6.67 & Establish communications and initialize systems. \\
\hline 2 & 13.33 & Move into position and cross obstacle zone. \\
\hline 1 & 6.67 & Move into position and prepare for mining. \\
\hline 6 & 40 & Mining \\
\hline 2 & 13.33 & Retract excavation system and cross obstacle course. \\
\hline 2 & 13.33 & Position Lunabot at the hopper. \\
\hline 1 & 6.67 & Deposit regolith. \\
\hline 15 & 100 & Total \\
\hline
\end{tabular}

The inclusion of a system hierarchy in the technical merit rubric allows the teams to demonstrate the organization of their system into subsystems, elements, and, for some representations, down to the part level. Most of the submitted system hierarchies followed an engineering discipline approach, as exemplified in Figure 2. The Montana State paper also noted that the second tier of subsystems was "further divided into functional units on the third level. Each of these units handles a specific task on behalf of the robot (e.g. 'Supply power' or 'Move the robot over the regolith')."6

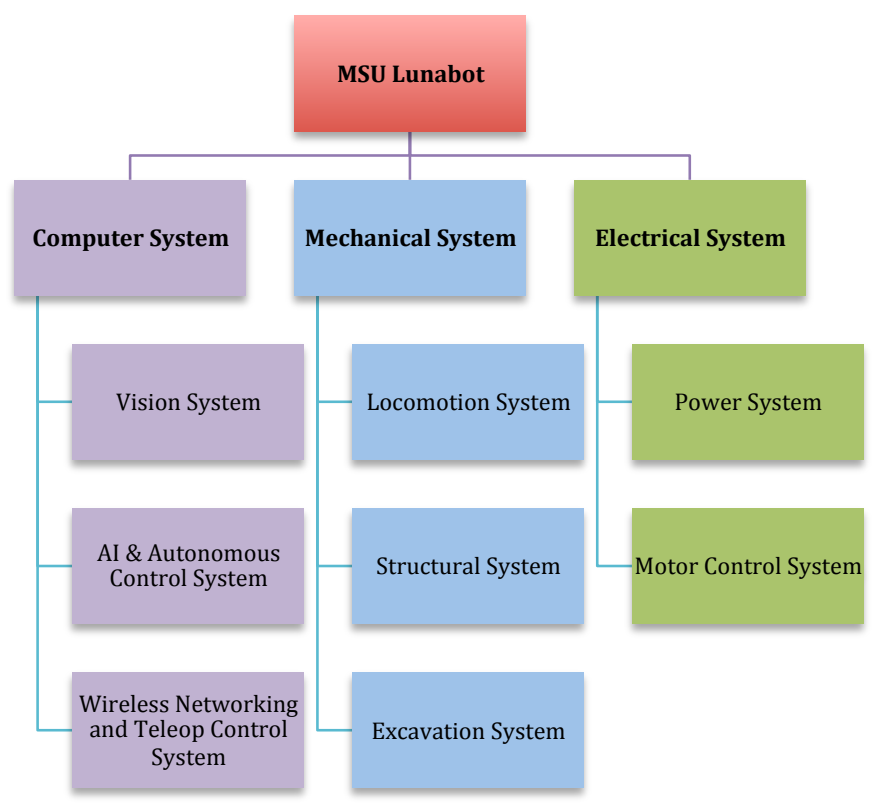

Figure 2 - Example system hierarchy for the Montana State University ALE Project ${ }^{6}$.

As an extension of the system hierarchy, the Montana State system interfaces diagram, Figure 3, displayed the subsystem relationships in terms of mechanical, electrical and data interfaces. Rather than create interface control documents the Montana State team used regular meetings of the different subsystems teams to address compatibility and interface changes. 


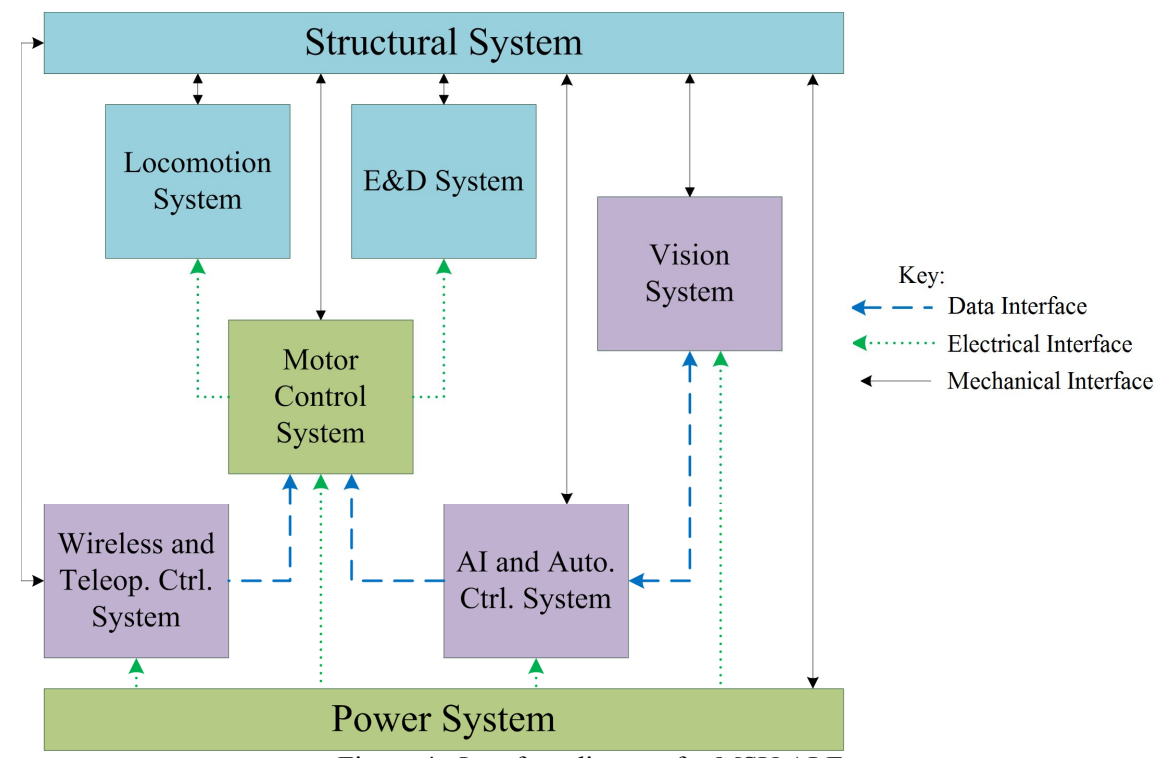

Figure 3 - Example interface diagram for the Montana State University ALE Project ${ }^{6}$.

The systems hierarchy and interfaces analyses highlight the interdisciplinary nature of systems engineering. Although not included in the systems engineering paper scoring rubric, the judges recognize the importance of this factor. Teams are required to document the number and types of engineering disciplines as part of their overall submission. The three winning teams in systems engineering included both mechanical and electrical engineering students, with the Montana State and Auburn teams adding members from software or computer engineering. The inclusion of different disciplines enables the application of different tools and mindsets, as well as faculty talent.

The most difficult rubric element for students to address is the requirements definition. The majority of past papers simply reiterated the NASA-imposed Lunabotics mining competition rules. A discriminator for winning systems engineering papers has been the derivation of system requirements and inclusion of a plan for verifying them. The Auburn University paper ${ }^{4}$ designated their system requirements as functional, performance, interface, verification and supplementary, as shown in Table 4. The Auburn team derived the requirements for each subsystem and subsequent component from this set of system requirements and discussed those derived requirements as part of each subsystem's design. For example, the Auburn design of the Digger Arm subsystem was driven by the following derived requirements:

- The Digger Arm shall lift the simulant at least $1 \mathrm{~m}$.

- The Digger Arm shall collect at least $10 \mathrm{~kg}$.

- The Digger Arm shall be fabricated with salvaged parts.

In turn, the Digger Arm comprised the arm boom and the bucket components, each with a unique set of requirements. The following were the additional key driving requirements pertaining to the design of the bucket subsystem.

- The Bucket shall dig with at least $22 \mathrm{kPa}$ at the tip of the bucket.

- Requirement derived from regolith simulant technical paper

- The collected regolith shall not cause the rover to tip forward. 
- The bucket shall pitch forward at least 145 degrees with respect to the horizontal.

- The bucket actuator shall support no more than $500 \mathrm{lbs}$.

The Auburn team's bucket design was driven by the specific requirements above, as well as the overall requirement of being sturdy, yet lightweight to earn additional points for minimizing system mass.

Table 4 -Example systems requirements list from the Auburn University paper ${ }^{4}$.

\begin{tabular}{|c|c|}
\hline $\begin{array}{l}\text { Requirement } \\
\text { designation }\end{array}$ & System Requirement \\
\hline Functional & The excavator shall collect, transport, lift and deposit the lunar simulant. \\
\hline Functional & The excavator shall be operated via telecommunications. \\
\hline Performance & The excavator shall collect at least $10 \mathrm{~kg}$ of simulant in 15 minutes. \\
\hline Performance & $\begin{array}{l}\text { The excavator shall lift the simulant at least one meter above the surface of the playing } \\
\text { field. }\end{array}$ \\
\hline Interface & The communication system shall interface with NASA's wireless network. \\
\hline Verification & $\begin{array}{l}\text { The prototype excavator shall be tested according to the functional requirements on or } \\
\text { before } 26 \text { February } 2010 \text {. }\end{array}$ \\
\hline Verification & $\begin{array}{l}\text { The final design of the system shall be verified according to the Competition Rule Book } \\
\text { requirements on or before } 01 \text { May } 2010 \text {. }\end{array}$ \\
\hline Supplementary & The excavation hardware must be equipped with an emergency stop. \\
\hline Supplementary & $\begin{array}{l}\text { The excavation hardware must be able to operate under semi-lunar like conditions as } \\
\text { described by Rule } 25 \text { of the Competition Rule Book. }\end{array}$ \\
\hline Supplementary & $\begin{array}{l}\text { The excavation system shall be designed, fabricated, and verified using less than } \\
\$ 5000.00 \text {. }\end{array}$ \\
\hline
\end{tabular}

The Auburn team's professional treatment of deriving requirements throughout the system, subsystems and components of their design also contributed to their trade-off assessments. Each trade study was performed and critiqued according to the relevant requirements. For example, the bucket design structure trade study, as characterized in the Table 5 decision matrix, focused on the weight and strength derived requirements. The result was stated as follows: "the decision matrix indicated that an aluminum bucket with a sub frame would best suit the bucket design based on the derived requirements." 
Table 5 -Example decision matrix for the bucket subsystem from the Auburn University paper ${ }^{4}$. Note - Importance: 1 =negligible, 5=significant; Material Capability: $1=$ poor, $5=$ excellent .

\begin{tabular}{|l|c|c|c|c|}
\hline $\begin{array}{l}\text { Property / Structures } \\
\text { Approach }\end{array}$ & Steel & $\begin{array}{c}\text { Sheet } \\
\text { AL }\end{array}$ & $\begin{array}{c}\text { Body on } \\
\text { Frame }\end{array}$ & Importance \\
\hline Rigid \& strength & 5 & 2 & 3.5 & 4 \\
\hline Weight & 1 & 5 & 4.5 & 5 \\
\hline Fab \& install ease & 4.5 & 4 & 3.5 & 2 \\
\hline Total score & 34 & 41 & 43.5 & -- \\
\hline
\end{tabular}

The Montana State University paper also relied on decision matrices to make design decisions, as they explained: "A decision matrix explores each option's ability to meet the design requirements, and provides a formal means of rating and comparing the options." 6 Table 6 shows their trade study for the excavation and deposition subsystem, with the design criteria and related requirements in the left column. As a result of their evaluation, "the MSU team chose the drum, which, though difficult to manufacture, greatly simplifies the digging and control system." It can be assumed that each decision matrix represents research and analysis by the student teams to assess the appropriate design options in a disciplined manner. The winning papers clearly demonstrated the trade-off assessments of the key subsystems that enabled an effective system design.

Table 6 -Example decision matrix for the excavation and deposition subsystem from the Montana State University paper ${ }^{6}$.

\begin{tabular}{|l|c|c|c|}
\hline $\begin{array}{l}\text { Design characteristic/ } \\
\text { subsystem options }\end{array}$ & Drum & Shovel & Belt/Bucket \\
\hline Cost & 3 & 3 & 2 \\
\hline Reliability & 4 & 2 & 1 \\
\hline Design Complexity & 3 & 4 & 1 \\
\hline Power consumption & 3 & 4 & 2 \\
\hline Weight & 3 & 3 & 1 \\
\hline Ease of autonomous control & 5 & 4 & 5 \\
\hline Dust mitigation Capacity & 5 & 3 & 1 \\
\hline Regolith Collection Cotal & 4 & 3 & 5 \\
\hline Manufacturability Try & 3 & 4 & 2 \\
\hline \multicolumn{2}{|r|}{} & 30 & 20 \\
\hline
\end{tabular}

Another discriminator in high-scoring papers is the treatment of the risk assessment rubric element. The winning papers use a quantitative approach to risk assessment, identifying mitigations for recognized risks with a high probability of occurrence. The Auburn University paper ${ }^{4}$ provided a risk assessment, as in Table 7, for each of their lunabot's primary subsystems. The team applied a standard failure-classification code taught by Auburn faculty ${ }^{7}$ and characterized as follows: 
- Code 4: Mission Failure-If this error cannot be mitigated, the mission will be a failure; no communications to the ground.

- Code 3: Reduced Lifetime - If this error cannot be mitigated, the mission is still a success, but further research is needed to extend mission lifetime in future missions.

- Code 2: Reduced Capability-If this error cannot be mitigated, the mission is still a success, but further research is needed to provide increased capability.

- Code 1: Non-Critical-If this error occurs, the primary mission could still be accomplished without additional need for redundancy.

This type of risk assessment allows students to recognize design features that may require redundancy, different assembly approaches, or alternative operational procedures. By exercising mitigation strategies, the university teams ensure a better chance for success in the actual mining competition.

Table 7 - Example risk management for the drive subsystem from the Auburn University paper $^{4}$.

\begin{tabular}{|l|l|c|l|}
\hline Components & Failure/Result & Code & Mitigation \\
\hline Nuts; bolts & Loose nuts \& bolts in components & 2 & Locking nuts \\
\hline Treads & Tread derails/tears & 3 & Four driving motors \\
\hline Chain for one motor & Drive chain derails & 2 & Chain guard \\
\hline $\begin{array}{l}\text { Drive sprocket on one } \\
\text { motor }\end{array}$ & Drive sprocket slips & 3 & $\begin{array}{l}\text { Semi-permanent } \\
\text { fastening }\end{array}$ \\
\hline Chain for two motors & Drive chain derails & 3 & $\begin{array}{l}\text { Semi-permanent } \\
\text { fastening }\end{array}$ \\
\hline $\begin{array}{l}\text { Drive sprocket for two } \\
\text { motors }\end{array}$ & Drive sprocket slips & 3 & Drive slower \\
\hline Motor on one side & Motor failure & 3 & Drive slower \\
\hline Two motors & Motor failure & 2 & Mount failsafe \\
\hline Motor mounts & Unsupported drive motors & & \\
\hline
\end{tabular}

\section{The judges' perspective}

As in any university-level paper competition, there are some excellent submittals, along with mediocre and even horrendous submittals. The purpose of the systems engineering paper competition is to encourage student teams to apply systems engineering processes during the design and verification phases of their work. The intent is for students to document their efforts while implementing systems engineering practices throughout the many months of their capstone design class. Unfortunately, most teams do not actively use systems engineering processes, but instead write their paper to match the rubric after the design and build of their lunabot. Such behavior completely misses the point of the paper as a required element of the competition. In fact, one student mentioned that she was responsible for writing the paper, and upon completion she realized that the systems engineering processes could have helped the team design a better 
lunabot. Even worse, some teams completely ignore the rubric and submit a paper reflecting part of their course requirements or a paper written at the last minute.

Table 8 shows the distribution of scores for the 2010-2012 competitions from 91 papers, representing all U.S. team submissions. (Note that only U.S. university teams are included given their requirement to offer a capstone design experience.) From the judges' perspective, it is noticeable that several teams appeared not to take the paper submission seriously or not understand the rubric.

Table 8-Scoring results from the 2010, 2011, and 2012 systems engineering paper submissions from U.S. teams.

\begin{tabular}{|c|c|l|}
\hline $\begin{array}{c}\text { Number of papers } \\
\text { from the 91 US } \\
\text { submissions }\end{array}$ & $\begin{array}{c}\text { Percentage of total } \\
\text { submissions }\end{array}$ & $\begin{array}{l}\text { Scoring results } \\
\text { (out of 20 possible points) }\end{array}$ \\
\hline 13 & $14 \%$ & Non-compliant \\
\hline 22 & $24 \%$ & Average score $\leq 10$ \\
\hline 33 & $36 \%$ & Average score, $11-15$ \\
\hline 23 & $25 \%$ & $\begin{array}{l}\text { Average score } \geq 16, \text { worthy of } \\
2^{\text {nd }} \text { round of judging }\end{array}$ \\
\hline
\end{tabular}

As expected, most of the teams that submitted an excellent systems engineering paper also had a lunabot that performed well in the on-site mining competition. "Performing well" equates to successfully teleoperating their lunabot with some level of lunar simulant collection in the required time. Of the 23 papers that received a total score of 16 or higher, $16(70 \%)$ of the lunabots performed well in the competition. Of the 33 teams that submitted a paper that received a mediocre score of $11-15,15(46 \%)$ of the lunabots performed well in the on-site mining competition. Of the remaining entrants, only 11 out of $45(24 \%)$ performed well in the actual competition. It is not surprising that, as the systems engineering paper scores go down, so does the performance of the lunabot. So, how did the systems engineering paper winners perform in the on-site mining competition? Auburn University had a respectable showing with $6.6 \mathrm{~kg}$ accumulated in the allotted time, worthy of an honorable mention for the first year of the competition. John Brown University actually collected the minimum $10 \mathrm{~kg}$ of simulant in the 10 minute run. Montana State University also met the collection challenge, but extended their performance level by operating semi-autonomously. Clearly, the superior systems engineering efforts resulted in successful lunabots.

Many factors can account for poorly written university-level papers, with the primary factor being the lack of exposure to systems engineering practices. Most undergraduate engineering students are not formally taught systems engineering coursework, much less knowledge of professional practices. Even those students who are exposed to systems engineering are not necessarily familiar with the NASA approach and expectations. Therefore, it is not reasonable to expect students to write superb papers on this topic. To foster the learning and integration of systems engineering into the capstone design work, NASA provides several references to the 
students, including the NASA Systems Engineering Handbook ${ }^{8}$ and a complete set of materials for an undergraduate space systems engineering course ${ }^{2}$. However, it is not practical to expect students to take the time to thoroughly review these references and comprehend the topic while being overwhelmed by their capstone design course and the Lunabotics challenge. From the judges' view, the best papers appear to be the result of faculty integrating the systems engineering concepts into the capstone curriculum, so that the students learn the critical concepts and practice them real-time during the Luabotics design challenge. In fact, a faculty member commented in the $2^{\text {nd }}$ year of the competition that he noticed a marked improvement in his students' paper submission once he started teaching the referenced space systems engineering course as part of the capstone experience.

Based on judges' feedback, the rubric for the 2013 systems engineering paper competition has received a major overhaul to steer the teams towards writing better papers. The directions now explicitly state that the paper should discuss the systems engineering methods used to design and build their lunabot. A variety of references for systems engineering is included on the rubric page, and the competition website, for easy student and faculty access. More points are given for technical topics, and fewer points for formatting (the content category). Appendices are now allowed up to five pages to enable the students to include more data, graphs and tables. Some topics in the intrinsic merit category - cost budget, technical budget, design philosophy and schedule-have guidelines to help the students understand what is expected. A few systems engineering topics have been removed from the rubric to allow the students to delve deeper into elements that are more typical for a capstone design course. Topics removed include the introduction, deliverables list, design margins, requirement flow-down to validation and checkout, and the system life cycle. Meanwhile, the basis of design has been changed to design philosophy in the context of systems engineering plus discussing design optimizations such as weight, automation and regolith capacity. International teams are also advised to have their papers reviewed to reduce translation and grammatical errors. Perhaps the biggest motivator for a polished student submission is the new requirement for the sponsoring faculty advisor to sign a statement certifying that he/she has reviewed and approved the paper prior to submission to NASA.

The judges appreciate the opportunity to read, evaluate, and discuss the systems engineering papers. They also appreciate how well the teams are doing in handling an extremely complex engineering job. The judges volunteer for this responsibility with the intent of helping the students prepare for their future careers as engineers. All positive and negative feedback is provided to the students in a constructive manner, in hopes that lessons will be learned for future competitive teams. The judges are looking forward to significant improvements from the teams based on the revised rubric.

\section{Conclusion}

The benefit of capstone design projects in undergraduate engineering curricula is undisputed. This paper recommends the inclusion of systems engineering learning as an integral part of implementing capstone design, using the Lunabotics Mining Competition design challenge as testimony. The systems engineering paper addition to the Lunabotics challenge enables students, faculty, and the NASA judges to develop greater insight into the teams' systems engineering practices and processes. In the best teams, the paper parallels actual systems engineering, giving 
their students practical systems engineering experience, along with the insight. As shown by the higher rate of successful excavation (if not actual mining victory) among the lunabots of teams with high-scoring systems engineering papers, thoughtful application of these processes correlates with better designs. In a world that requires more complex and interrelated systems to address more ambitious objectives, understanding of and fluency in systems engineering provides a distinct advantage.

\section{Bibliography}

1. Rahmatian, L. et al., "Soil Test Apparatus for Lunar Surfaces", American Society of Civil Engineers, Earth and Space 2010: Engineering, Science, Construction and Operations in Challenging Environments, 2010. http://www.nasa.gov/pdf/679094main_BP-1\%20Soil\%20Testing\%20(2).pdf

2. Space Systems Engineering. http://www.spacese.spacegrant.org

3. Auburn University capstone design course. http://www.nasa.gov/offices/education/centers/kennedy/technology/LunarRegolithExcavatorSeniorDesign Course.html

4. Colbert, J. et al., "Lunabotics Mining Competition Systems Engineering Paper", Samuel Ginn College of Engineering, Auburn University, Auburn, AL, 2010.

5. Anthes, M. et al., "Lunar Regolith Excavator Systems Engineering Paper", Department of Engineering, John Brown University, Siloam Springs, AR, 2011.

6. Benson, D. et al., "The Montana ALE (Autonomous Lunar Excavator) Systems Engineering Report", Department of Engineering, Montana State University, Bozeman, MT, 2012.

7. Beale, D. and Bonometti, J. "Chapter 2: Systems Engineering (SE) - The Systems Design Process". http://www.eng.auburn.edu/ dbeale/ESMDCourse/Chapter2.htm

8. NASA Systems Engineering Handbook; SP-2007-6105 Rev 1; December 2007. 